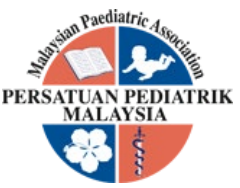

\title{
UNILATERAL CONGENITAL CHOANAL ATRESIA: A RARE MISSED CAUSE OF CHRONIC NASAL DISCHARGE
}

\author{
Wan Nur Anis Wan Draman ${ }^{1,2}$, Addina Mat Baki ${ }^{2}$, Hashimah Ismail ${ }^{2}$, Shamina Sara Moses ${ }^{2}$, \\ Irfan Mohamad'
}

\begin{abstract}
Choanal atresia is an uncommon malformation of the upper airway. Bilateral choanal atresia usually detected earlier as it is often associated with severe asphyxia immediately after birth. The diagnosis is often delayed in unilateral type, and mostly presented with unilateral chronic nasal discharge. This condition is rarely encountered but should be considered as a possible differential diagnosis of persistent nasal discharge. We present a case of unilateral congenital choanal atresia in a 4-month-old baby girl presented with persistent unilateral nasal discharge. Diagnostic investigation and possible surgical treatment techniques were discussed.
\end{abstract}

\section{Keywords:}

Choanal Atresia, Unilateral Nasal Discharge, Endoscopic Repair

\section{Introduction}

Choanal atresia (CA) is a congenital craniofacial anomaly characterised by a complete obliteration of the posterior choanae. It can be unilateral or bilateral, and either complete or incomplete. The most common obstructions are purely bony, but it may be membranous or a combination of the two [1]. Bilateral CA usually presented with immediate severe airway obstruction in neonates since they are an obligate nasal breather. This condition can lead to death from suffocation. Unilateral type usually presents later in life with the commonest symptoms are unilateral chronic rhinorrhoea and rarely causing feeding difficulties or airway symptoms [2].

\section{Case Report}

A 4-month-old girl was referred for chronic unilateral right nasal discharge since birth. She had an excessive unilateral persistent daily nasal discharge from the right nostril with no history of preceding upper respiratory tract infection. The symptom did not resolve instead of continuous normal saline nasal drop. Nasal discharge was thick and clear mucous without blood stained. Otherwise she had good weight gaining with no
Received: 26 April 2020 ; Accepted revised manuscript: 19 June 2020

Published online: 25 June 2020 history of nasal blockage, noisy breathing, shortness of breath, interrupted breastfeeding and cyclical cyanosis. The child was born full term via uneventful spontaneous vaginal delivery to a healthy mother.

Physical examination revealed a non-syndromic, active baby girl, with no respiratory distress or stridor. She had normal motor and behaviour development that were correspond to normal growth curve. Clinical examination of nasal cavity showed absence of air misting on right nostril from cold spatula test, and presence of clear, nonfoul smelly thick mucus nasal discharge without visible mass on right nostril. Failure insertion of a 6 F Ryles tube catheter up to $3 \mathrm{~cm}$ through right nostril highly suggestive for a diagnosis of unilateral CA. Computed tomography (CT) scan of paranasal sinus confirmed diagnosis by showing unilateral bony plate, thickened vomer and narrowed right posterior choanae

'Department of Otorhinolaryngology-Head \& Neck Surgery, School of Medical Sciences, Universiti Sains Malaysia, Kelantan, Malaysia

${ }^{2}$ Department of Otorhinolaryngology-Head \& Neck Surgery, Hospital Raja Perempuan Zainab Il, 15586 Kota Bharu, Kelantan, Malaysia

Corresponding author: Assoc. Prof. Dr. Irfan Mohamad Department of Otorhinolaryngology-Head \& Neck Surgery, School of Medical Sciences, Universiti Sains Malaysia, Kelantan, Malaysia

Tel: 609-7676420 Email: irfankb@usm.my 
measuring $2 \mathrm{~mm}$ in width at the level of pterygoid plate (Figure 1). The left side was normal.

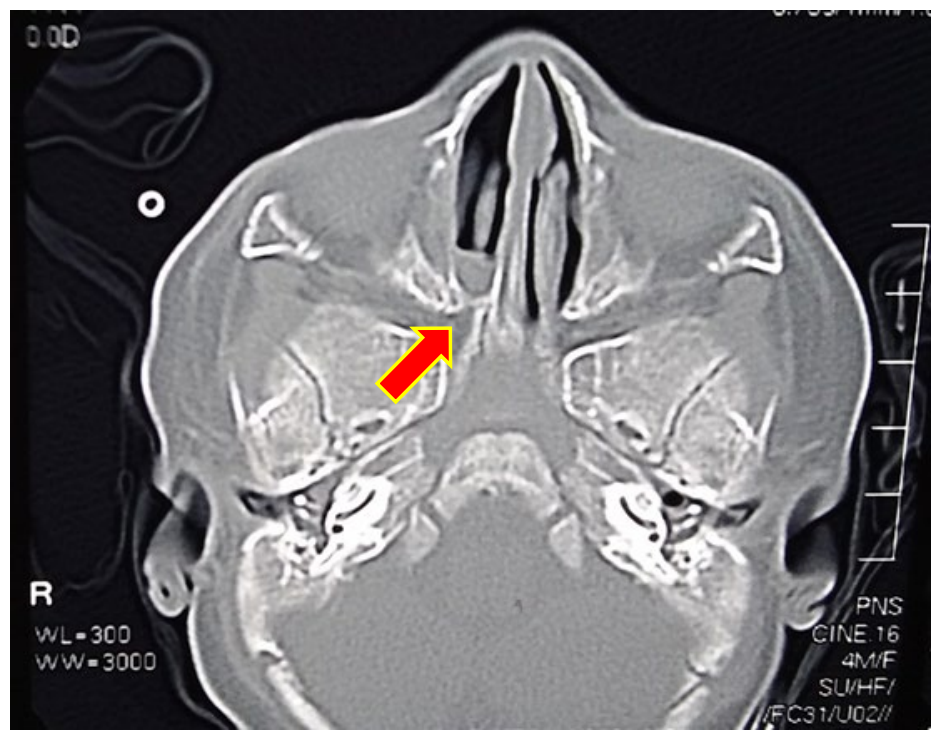

Figure 1. View of axial CT showed narrowing of right posterior choanae with thickening of vomer (arrow)

Parent was counselled and informed consent was obtained for endoscopic transnasal choanal repair under general anaesthesia aiming to relieve nasal obstruction and resolved symptoms of nasal discharge. After oral intubation and throat pack insertion, nasal decongestion using neurosurgical patty was done. Local anaesthesia of diluted Marcaine-adrenaline was infiltrated at surrounding mucosa. Mucosa was debrided using microdebrider with diameter of $4 \mathrm{~mm}$. Intraoperatively revealed a mixed type of right $C A$, with bony dehiscence at inferomedial aspect of the atresia (Figure 2). Atretic bony plate was drilled using skeeter diamond burr size 3 . Nasopharyngeal airway size 4 was placed in-situ for one week as a stent to maintain the patency of choanal opening (Figure 3).

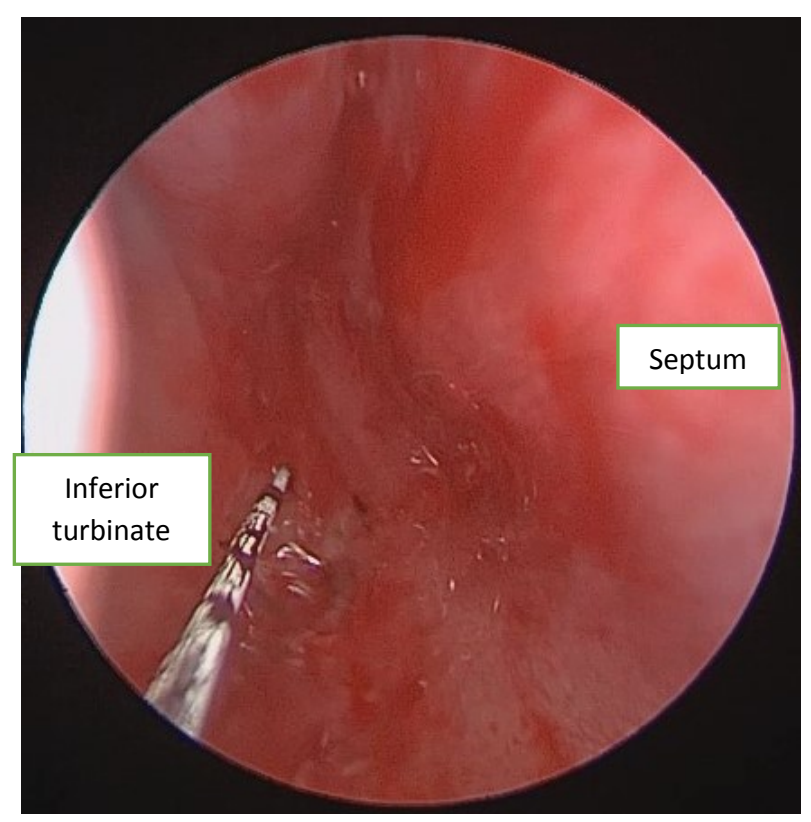

Figure 2. Intraoperative finding showed complete atresia of right posterior choana. 


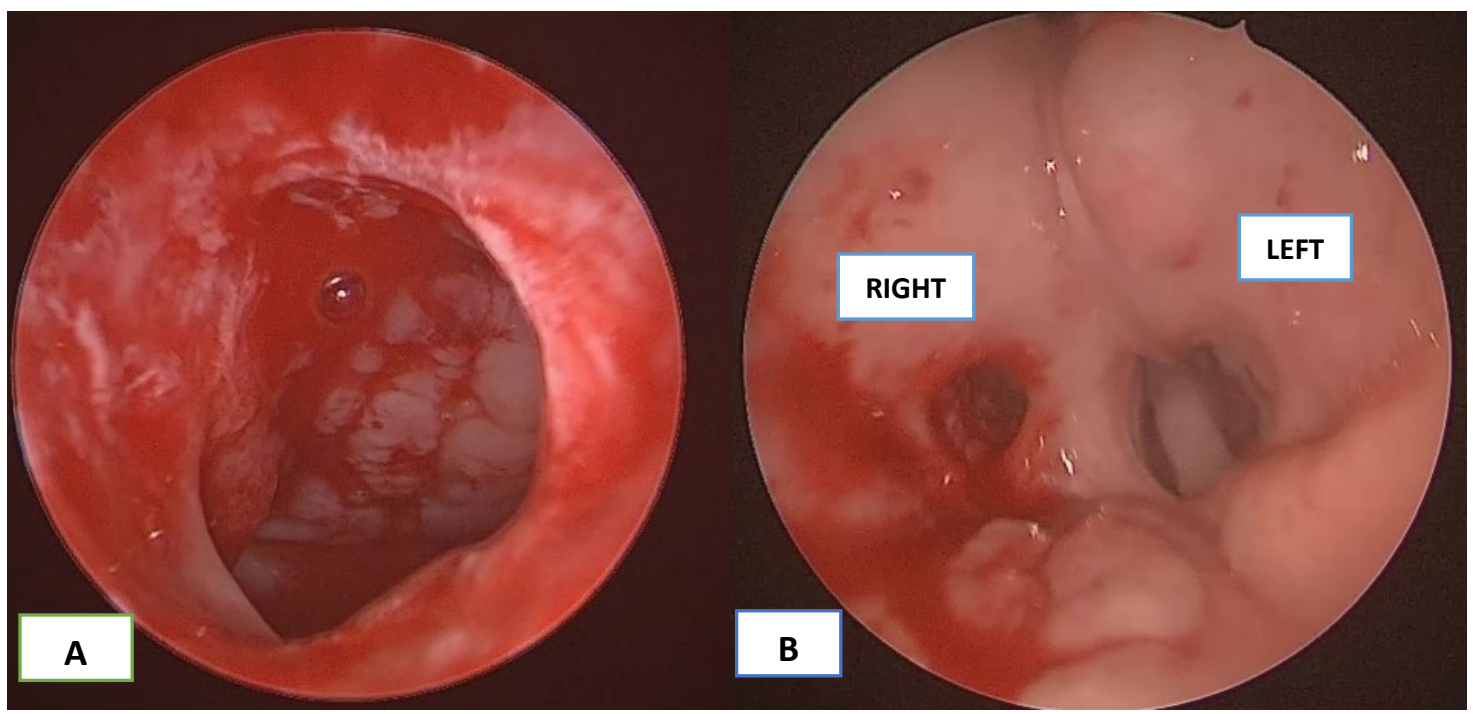

Figure 3. Transnasal endoscopic view showed adequate opening at posterior choanae post endoscopic transnasal repair (A). Endoscopic view from nasopharynx after repair using $120^{\circ}$ rod lens telescope comparing patency between right and left posterior choanae (B).

During 4 months follow up there was restenosis, which required second endoscopic transnasal repair. Membranous tissue was debrided. Dexamethasone was infiltrated at the surrounding opening. Nasopharyngeal airway size 4 was placed for 2 weeks. The child was doing well after surgery. Initially, follow-up given weekly for nasal toileting and stent was removed in clinic at 2 weeks after operation. Subsequent monthly follow up given for 2 months followed by 3 monthly follow up. Evaluation at 18 months post operation showed she had no more symptoms of nasal discharge and both choanae remained patent on flexible nasoendoscopic examination.

\section{Discussion}

Choanal atresia (CA) is a congenital malformation of the posterior nasal aperture characterised by a complete obliteration of the posterior choanae that blocks the air flow from nose to nasopharynx. It occurs in the true choana at posterior end of the bony septum, which is anatomically about $3 \mathrm{~cm}$ at birth from the nostrils (Figure 4).

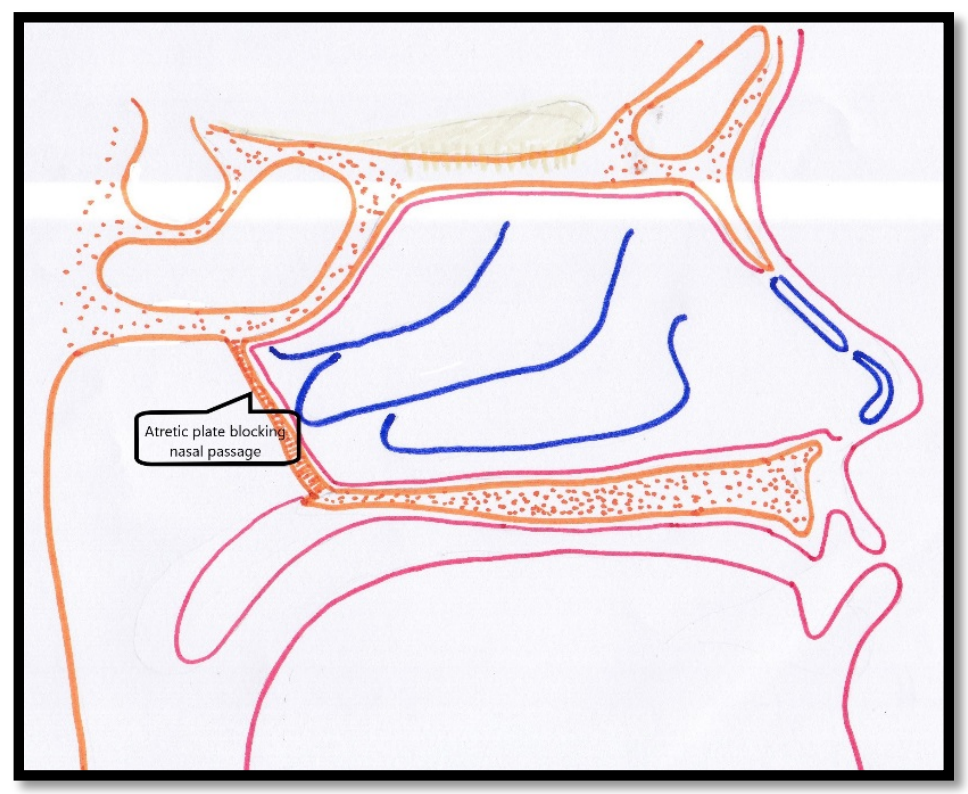

Figure 4. A schematic picture of atresia located at posterior choana which anatomically about $3 \mathrm{~cm}$ from the nostril. (Text in the Figure 4:Atretic plate blocking nasal passage) 
This rare condition is seen in 1 to 2 in 10,000 live births, with a male-to-female ratio of 2:1 [3]. Unilateral CA is more common affecting $65 \%$ to $75 \%$ patients with higher prevalence on the right side [4]. Bilateral CA affecting $75 \%$ of patients is associated with other congenital abnormalities such as CHARGE, Treacher Collins, Crouzon, and Pfeiffer syndromes $[3,4]$.

The exact aetiology is not clear, although four theories were proposed: (i) persistent buccopharyngeal membrane; (ii) persistent nasobuccal membrane of Hochstetter; (iii) abnormal persistence of mesoderm creating adhesions of the nasal choanal region; and (iv) the concept of misdirected mesodermal flow secondary to local embryologic factors [5]. This may result in complete bony occlusion of the choana (a true bony $(A)$, bony stenosis with a membranous component (a mixed bonymembranous (A) and complete membranous with no significant bony component (membranous CA). Approximately $90 \%$ of CAs are bony or mixed, while only $10 \%$ are pure membranous [2]. This can be detected by CT imaging showing the nature of the atretic plate that cover posterior choana. The case presented in this report had mixed type CA. The differential diagnosis in this case include rhinolith, foreign body and sinonasal tumours (Table 1).

Table1. The differential diagnosis in this case include rhinolith, foreign body and sinonasal tumours

\begin{tabular}{|c|c|c|c|c|}
\hline & Unilateral CA & Rhinolith & Foreign body nose & Sinonasal tumour \\
\hline Aetiology & $\begin{array}{l}\text { Congenital } \\
\text { malformation of } \\
\text { posterior nasal } \\
\text { aperture }\end{array}$ & $\begin{array}{l}\text { Calcification within } \\
\text { nasal cavity due to } \\
\text { presence of a } \\
\text { foreign body }\end{array}$ & $\begin{array}{l}\text { Presence of an organic or } \\
\text { inorganic object in the } \\
\text { nose }\end{array}$ & $\begin{array}{l}\text { Growth in the nasal } \\
\text { cavity arising from } \\
\text { mucosal lining }\end{array}$ \\
\hline $\begin{array}{l}\text { Age of } \\
\text { presentation }\end{array}$ & Newborn or infant & Toddler & Toddler & Elder children \\
\hline $\begin{array}{l}\text { Nasal } \\
\text { discharge }\end{array}$ & Clear, thick mucus & $\begin{array}{l}\text { Bad smelly } \\
\text { mucopurulent }\end{array}$ & $\begin{array}{l}\text { Depend on duration and } \\
\text { material of foreign body }\end{array}$ & $\begin{array}{l}\text { Blood stained } \\
\text { discharge }\end{array}$ \\
\hline Air misting & Absence & $\begin{array}{l}\text { Reduced depend } \\
\text { on size }\end{array}$ & Reduced depend on size & $\begin{array}{l}\text { Reduced depend on } \\
\text { tumour size }\end{array}$ \\
\hline $\begin{array}{l}\text { Nasal } \\
\text { endoscopy }\end{array}$ & $\begin{array}{l}\text { Presence of atretic } \\
\text { plate at posterior } \\
\text { choana }\end{array}$ & $\begin{array}{l}\text { Presence of } \\
\text { concrete in nasal } \\
\text { cavity }\end{array}$ & $\begin{array}{l}\text { Presence of foreign body } \\
\text { commonly at mid nasal } \\
\text { part }\end{array}$ & Presence of mass \\
\hline Imaging & $\begin{array}{l}\text { Bony/membranous/ } \\
\text { mixed atretic plate at } \\
\text { posterior nasal space }\end{array}$ & $\begin{array}{l}\text { Hyperdense lesion } \\
\text { in CT scan }\end{array}$ & $\begin{array}{l}\text { Hyperdense/hypodense } \\
\text { lesion depend on material } \\
\text { of foreign body }\end{array}$ & $\begin{array}{l}\text { Soft tissue opacity } \\
\text { with bony erosion } \\
\text { involving } \\
\text { surrounding } \\
\text { paranasal sinuses }\end{array}$ \\
\hline
\end{tabular}

Unilateral CA often presents later in life with mild unilateral chronic rhinorrhea, in which feeding difficulties or airway symptoms are rare. There were few reported cases of delayed diagnosis of $C A$ in adult life with the main presenting complaints include unilateral nasal discharge, snoring and nasal blockade [6]. The subject in our case had no other problem thus causing delayed in seeking treatment.

Since newborns are obligatory nasal breathers, bilateral CA mostly present with cyclical respiratory distress and cyanosis, which is relieved by crying, together with feeding difficulties.
Mouth breathing is a learned response which develops approximately four to six weeks after birth. Subjects with bilateral CA has lifethreatening risk of developing asphyxia in bilateral $C A$, or in unilateral atresia when the opposite nostril is obstructed.

The initial screening for CA includes observing a cotton wisp placed in front of the nostril, listening for breath sounds using a stethoscope and looking for misting on a mirror or a silvered surface. On anterior rhinoscopy, the occluded nasal cavity will be filled with thick, tenacious, translucent secretion. Failure to pass a fine 
catheter such as $5 \mathrm{~F}$ Ryles tube along the nose beyond $32 \mathrm{~mm}$ from the nostril is a simple and reliable test. The subject in our case showed all these positive findings.

Flexible nasal endoscopy allows direct visualization of the point of obstruction in the nasal passage and confirms the presence of an atretic plate in the choana. Nasal decongestion and mucous suctioning must be performed prior endoscopic examination to provide an excellent endoscopic view. Rhinography is a classic method for diagnosing CA. This procedure involves the administration of radiopaque dye into the nasal cavity and radiologic imaging is performed while the patient is in the supine position. A simple method for screening newborn with congenital CA using automatic tympanometer, with 100\% sensitivity and specificity has been reported in the literature [7].

Paranasal sinus CT scan is the standard diagnostic imaging. It is fast, less invasive and assist in confirming the diagnosis by demonstrating the site of the obstruction, its thickness, height and determining the types of the atresia. Careful suctioning and application of a topical decongestant is important prior to imaging to clear the excess viscous secretion that filled the occluded nasal cavity. This can provide better imaging and obscure the true thickness of the membranous occlusion [6]. The CT findings include medialisation of the lateral pterygoid plate, enlarged vomer with vomer width more than $0.55 \mathrm{~cm}$ and obstruction of the posterior choanale orifice as observed in subject of our case.

Treatment can be divided into emergency and elective definitive categories. Bilateral CA in a neonate needs immediate resuscitation such as by inserting an oral airway to break the seal formed by the tongue against the palate. The patients will need to adapt and learn mouth breathing using the McGovern nipple. In an emergency, intubation maybe needed and the occluding septum may be perforated carefully with a straight trocar or urethral sound followed by widening the opening using the side biting rongeurs. Unilateral CA normally requires conservative management and surgery can be planned later.

In 1854, Emmert reported the first successful surgical procedure for congenital CA in a 7-yearold boy using a curved trocar transnasally [8]. Since then, several surgical approaches have been described to correct CA including transnasal, transpalatal, transseptal, sublabial transseptal, transantral, and external rhinoplasty [1]. Endoscopic transnasal approach using a $120^{\circ}$ telescope was used to visualise an atretic plate from nasopharynx. Perforation of the atretic plate can be done using straight urethral sounds followed by a drill using cutting or diamond burr to remove the bony component [1]. High-speed microdebriders provide clearer operative fields and causing less tissue trauma for experienced surgeons. Our patient showed successful outcome by endoscopic transnasal repair using microdebrider followed by placing a stent.

Transpalatal repair is a technique that can provide excellent exposure and has a high success rate up to $84 \%$ but have significant potential complications and requires more operative time [9]. Palatal exposure maybe obtained using Brown-Davis or Dingmans self-retaining retractors. Significant blood loss and the possible occurrence of palatal fistula, palatal dysfunction, and maxillofacial growth disturbance are complications that can be encountered.

The use of stents in the treatment of patients with $\mathrm{CA}$ is controversial. Some surgeons used stents to stabilise the nasal passage in the post-operative period and to prevent narrowing of the newly formed lumen as it heals. However, stents can be the nidus for infection and may induce a foreign body reaction which may contribute to restenosis. Therefore, the use of stents following repair requires prophylactic antibiotic and antireflux medications. Nasal stenting for approximately 6 weeks showed good outcome with low revision rates [2]. However, Cochrane review reported no difference in patency rates for patients who receive or do not receive stenting after surgery [10].

Our patient was on nasal stent for a week in her first surgery which was complicated with restenosis which required revision surgery. In the second operation, stent was placed for longer duration which is about 2 weeks. Regular suction and local care of stent are important to ensure patency of tube for breathing. Removal of stents need to be done under general anaesthesia and granulation tissue need to be removed followed by steroid injection. Mitomycin C also can be used as an adjunct to surgical repair by reducing fibrosis and prevent restenosis [10]. As an alternative to the stent use, repeated balloon dilatation after the endoscopic transnasal repair has shown a statistically significant improved outcome [11]. 
Another current alternative technique includes helium: YAG laser, carbon dioxide laser or potassium titanyl phosphate (KTP) lasers that can provide an easy, quick and create minimal discomfort for the patient [12]. Patient only need short hospitalisation and the operation can be repeated if a good result is not initially achieved. Most importantly, a stent is not usually needed.

\section{Conclusion}

Unilateral congenital CA is a rare entity and it should be considered in children with chronic persistent nasal discharge for duration more than 12 weeks. Nasal endoscopy and preoperative CT are the gold standard to confirm the diagnosis and to guide surgical procedure. Endoscopic transnasal repair followed by nasal stenting is the management of choice with possibility for postoperative restenosis complication, thus warrant a well-planned long-term follow up.

\section{References}

[1] Friedman N, Mitchell R, Bailey C, Albert D, Leighton $S$. Management and outcome of choanal atresia correction. International Journal of Pediatric Otorhinolaryngology. 2000; 52(1):45-51.

[2] Wiatrak BJ. Unilateral choanal atresia: initial presentation and endoscopic repair. International Journal of Pediatric Otorhinolaryngology. 1998;46(1-2):27-35.

[3] Case AP, Mitchell LE. Prevalence and patterns of choanal atresia and choanal stenosis among pregnancies in Texas, 1999-2004. American Journal of Medical Genetics A. 2011;155A:786-91.

[4] Keller JL, Kacker A. Choanal atresia, CHARGE association, and congenital nasal stenosis. Otolaryngologic Clinics of North America. 2000;33(6):1343-51.

[5] Hengerer AS, Strome M. Choanal atresia: a new embryologic theory and its influence on surgical management. The Laryngoscope. 1982;92(8):913-21.

[6] Kwong KM. Current updates on choanal atresia. Frontiers in Pediatrics. 2015;3:52.

[7] Effat KG. Use of the automatic tympanometer as a screening tool for congenital choanal atresia. The Journal of Laryngology \& Otology. 2005;119(2):125-8.

[8] Stamm AC, Pignatari SSN. Nasal septal crossover flap technique: a choanal atresia microendoscopic surgical repair. American Journal of Rhinology. 2001;15(2):143-8.

[9] Park AH, Brockenbrough J, Stankiewicz J. Endoscopic versus traditional approaches to choanal atresia. Otolaryngologic Clinics of North America. 2000;33 (1):77-90.

[10] Newman JR, Harmon P, Shirley WP, Hill JS, Woolley AL, Wiatrak BJ. Operative management of choanal atresia: a 15-year experience. JAMA Otolaryngology-Head \& Neck Surgery. 2013;139(1):71-5.

[11] De Vincentiis GC, Panatta ML, De Corso E, et al. Endoscopic treatment of choanal atresia and use of balloon dilation: our experience. Acta Otorhinolaryngolica Italica. 2020;40(1):44-9.

[12] Fong $M$, Clarke K, Cron C. Clinical applications for the holmium: YAG laser in disorders of the paediatric airway. Journal of OtolaryngologyHead \& Neck Surgery. 1999;28(6):337. 